\title{
2D-PAGE as an effective method of RNA degradome analysis
}

\author{
Martyna Nowacka · Paulina Jackowiak • Agnieszka Rybarczyk • \\ Tomasz Magacz $\cdot$ Pawel M. Strozycki $\cdot$ Jan Barciszewski • \\ Marek Figlerowicz
}

Received: 13 January 2011/ Accepted: 23 April 2011/Published online: 11 May 2011

(C) The Author(s) 2011. This article is published with open access at Springerlink.com

\begin{abstract}
The continuously growing interest in small regulatory RNA exploration is one of the important factors that have inspired the recent development of new high throughput techniques such as DNA microarrays or next generation sequencing. Each of these methods offers some significant advantages but at the same time each of them is expensive, laborious and challenging especially in terms of data analysis. Therefore, there is still a need to develop new analytical methods enabling the fast, simple and costeffective examination of the complex RNA mixtures. Recently, increasing attention has been focused on the RNA degradome as a potential source of riboregulators. Accordingly, we attempted to employ a two-dimensional gel electrophoresis as a quick and uncomplicated method of profiling RNA degradome in plant or human cells. This technique has been successfully used in proteome analysis. However, its application in nucleic acids studies has been very limited. Here we demonstrate that two dimensional electrophoresis is a technique which allows one to quickly and cost-effectively identify and compare the profiles of 10-90 nucleotide long RNA accumulation in various cells and organs.
\end{abstract}

Electronic supplementary material The online version of this article (doi:10.1007/s11033-011-0718-1) contains supplementary material, which is available to authorized users.

M. Nowacka · P. Jackowiak · T. Magacz ·

P. M. Strozycki · J. Barciszewski · M. Figlerowicz $(\square)$

Institute of Bioorganic Chemistry, Polish Academy of Sciences,

Noskowskiego 12/14, 61-704 Poznan, Poland

e-mail: marekf@ibch.poznan.pl

A. Rybarczyk · M. Figlerowicz

Institute of Computing Science, Poznan University

of Technology, Piotrowo 3A, 60-965 Poznan, Poland
Keywords RNA degradome $\cdot$ 2D-PAGE . Small non-coding RNA · RNA biomarkers

\section{Introduction}

The maturation, quality control and turnover of all types of transcripts are inseparably connected with RNA degradation. It secures a balance between RNA synthesis and RNA decay and provides cell homeostasis. For fulfilling its role RNA degradation has to be confined to a specific set of molecules, those unnecessary at given conditions, dysfunctional, or defective. On the other hand the RNA molecules essential for proper cell functioning should stay intact. This appears to be accomplished by strict and complex control mechanisms. Another inherent feature of RNA degradation is its high efficiency, which often precludes the identification of any intermediary products [1]. A rapid removal of any redundant RNA fragments is clearly advantageous since they have a potential to interfere with gene expression pathways [2,3]. However, there is accumulating evidence that the degradation of several types of mature RNAs (among them tRNA, rRNA and snoRNA) can yield stable intermediates [4-6]. What is more, it has been shown that at least some of these intermediates display regulatory functions $[7,8]$. These findings promote further research of stable intermediates of RNA degradation. All together these intermediates collectively constitute the RNA degradome. In consequence, demand for new methods of RNA degradome analysis is still increasing. Certainly, numerous approaches used for non-coding RNA characterization can be employed for this purpose. They cover a variety of techniques including the cloning and sequencing of RNA or hybridization-based methods such as northern blot and microarrays [9]. At present, next generation sequencing appears to 
prevail as the method of choice due to the great potential offered by available platforms [10]. Unfortunately, massive sequencing methods are laborious and expensive. They are perfect for a very detailed analysis of RNA degradome but too sophisticated for fast screening or comparison of several RNA degradomes. The latter can be done with DNA microarrays, provided that either all components of examined RNA degradomes were earlier cloned and sequenced or tiling microarrays covering the whole genome are available. Here we showed that two-dimensional polyacrylamide gel electrophoresis (2D-PAGE) can be employed for analyzing high copy number RNA degradants isolated from plant and human cells. The collected data indicate that one can use 2DPAGE to determine whether and to what extent the pattern of RNA degradant accumulation is tissue- or cell-specific. What is also important, the described method is relatively simple, quick and cost-effective. It seems that 2D-PAGE can also be used instead of one-dimensional electrophoresis to facilitate the fractionation of RNA degradome for more profound sequencing studies.

\section{Materials and methods}

Plants growth

Arabidopsis thaliana (ecotype Columbia-0) were grown in peat-filled pots at $22^{\circ} \mathrm{C}$ during the day and $20^{\circ} \mathrm{C}$ at night in a 8/16 h light/dark photoperiod [11]. Leaf and root samples collected from 5 -week-old plants were immediately frozen in liquid nitrogen and stored at $-80^{\circ} \mathrm{C}$. Lupinus luteus $\mathrm{L}$. cv. Ventus were grown in perlite-filled pots at $24 / 26^{\circ} \mathrm{C}$ during the day and $21 / 23^{\circ} \mathrm{C}$ at night in a $16 / 8 \mathrm{~h}$ light/dark photoperiod. A detailed description of growth conditions, lupin Bradyrhizobium inoculation and medium contents was previously published by Strozycki and coworkers [12, 13]. Non-infected, $\sim 5 \mathrm{~cm}$ long lupine roots were collected 9 days after germination. Symbiotic nodules were collected from lupine roots 9 days post-infection with Bradyrhizobium. Both root and nodule samples were immediately frozen in liquid nitrogen and stored at $-80^{\circ} \mathrm{C}$.

HeLa and HL60 cell line cultivation

HeLa cells were cultured at $37^{\circ} \mathrm{C}$ with $5 \% \mathrm{CO}_{2}$ in Dulbecco's modified Eagle medium (DMEM) (Gibco) supplemented with $10 \%$ fetal bovine serum (Sigma) and gentamycin $(100 \mu \mathrm{g} / \mathrm{ml})$. Cells were harvested in the logarithmic growth phase by trypsin/EDTA treatment and counted using Coulter Counter. They were then centrifuged, washed with PBS, immediately frozen in liquid nitrogen $\left(10^{6}\right.$ cells per tube $)$ and stored at $-80^{\circ} \mathrm{C}$. HL60 cells were cultured at $37^{\circ} \mathrm{C}$ with $5 \%$ $\mathrm{CO}_{2}$ in RPMI 1640 medium (Gibco) supplemented with $10 \%$ fetal bovine serum (Sigma) and gentamycin $(100 \mu \mathrm{g} / \mathrm{ml})$. Cells were harvested in the logarithmic growth phase and counted using Coulter Counter, then centrifuged, washed with PBS, immediately frozen in liquid nitrogen $\left(10^{6}\right.$ cells per tube) and stored at $-80^{\circ} \mathrm{C}$.

\section{RNA extraction}

RNA samples enriched in molecules shorter than $200 \mathrm{nt}$ were isolated from (i) A. thaliana leaves, (ii) L. luteus roots and nodules, and (iii) HeLa or HL60 cells using the mirVana miRNA Isolation Kit (Ambion). Subsequently, $1 \mu \mathrm{g}$ of RNA was labeled with $\gamma{ }^{32} \mathrm{P}$ ATP using T4 PNK Kinase (Fermentas) and subjected to electrophoresis in polyacrylamide gel.

\section{D-PAGE of small RNAs}

2D-PAGE was performed under: non-denaturing conditions (without urea), semi-denaturing conditions (4 M urea) or denaturing conditions (7 M urea). With minor modifications, we followed the procedure elaborated by Fradin et al. [14] (see also Online Resource Fig. 1). A 10\% polyacrylamide gel (10\% of acrylamide:bisacrylamide 19:1 solution; $1 \times$ buffer TBE $\mathrm{pH}=8.3 ; 0 / 4 / 7 \mathrm{M}$ urea, respectively; $0.1 \%$ APS; 0.1\% TEMED) was used for first dimension electrophoresis (1D-PAGE). The size of the gel was $60 \times 30 \times$ $0.04 \mathrm{~cm}$. 1D-PAGE was performed in $1 \times$ TBE buffer $(\mathrm{pH}=$ $8.3)$ at $300 \mathrm{~V}$ for $24-28 \mathrm{~h}$ at room temperature. A $\sim 25 \times 2.5 \mathrm{~cm}$ gel slice containing RNAs ranging in size between $\sim 12$ and $\sim 120$ nt was cut out from the gel (the length of RNA molecules was estimated based on the location of bromophenol blue and xylene cyanol), placed between new electrophoresis glasses, parallel to their shorter edge, and embedded in a freshly prepared $10 \%$ polyacrylamide gel (up to $\sim 1 \mathrm{~cm}$ below the slice). The remaining space between electrophoresis glass plates was filled with a freshly prepared $20 \%$ polyacrylamide gel $(20 \%$ of acrylamide:bisacrylamide 19:1 solution; $1 \times$ buffer TBE $\mathrm{pH}=8.3 ; 0 / 4 / 7 \mathrm{M}$ urea, respectively; $0.1 \%$ APS; $0.1 \%$ TEMED). The size of the 2D gel was as follows: $40 \times$ $30 \times 0.04 \mathrm{~cm}$. Second dimension electrophoresis was performed at $500 \mathrm{~V}$ for $23-24 \mathrm{~h}$ at room temperature. The gel was exposed to a phosphor screen which was subsequently scanned by a Fuji FLA-5100 imaging system.

\section{Cloning of RNA extracted from a gel}

After 2D-PAGE, RNA molecules accumulating to highest levels were visualized by autoradiography. Selected spots were excised from the gel, gel fragments were collected in 
one tube, and RNA was eluted (overnight in $0.3 \mathrm{NaCl}$ ). Gel extracted RNA was precipitated with ethanol and used for cDNA library construction (see also Online Resource Fig. 2).

A cDNA library of small RNAs was prepared based on the protocols elaborated earlier by Lau et al. [15], Chappell et al. [16] and Lee and Ambros [17]. The following adapter and primers were used for RNA cloning: $3^{\prime}$ End Donor Oligo (available from IDT Inc.- - miRNA cloning linker) 5'-AppCTGTAGGCACCATCAddA-3', 3' RT/PCR Primer 5'-ATTGATGGTGCCTAC-3', 5' RT/PCR Primer 5'-ATCGTAGGCACCTGAAAGGG- $3^{\prime}$. Gel purified RNAs were ligated with a $3^{\prime}$ End Donor oligonucleotide. The latter contains the BanI restriction site, has a blocked $3^{\prime}$-hydroxyl terminus (with dideoxyA) and a pre-activated $5^{\prime}$ terminus (by $5^{\prime}-5^{\prime}$ diphosphate $\mathrm{A}$ addition $-5^{\prime}$ adenylation). The ligation was performed using T4 RNA ligase (Promega) in the absence of ATP. Ligation products were separated in a $10 \%$ denaturing polyacrylamide gel (to remove the excess of the $3^{\prime}$-adapter) and eluted from the gel overnight in $0.3 \mathrm{M} \mathrm{NaCl}$ at $4^{\circ} \mathrm{C}$. Eluted RNA was precipitated with ethanol, dissolved in RNase-free water and subjected to reverse transcription. The reverse transcription reaction was performed using Superscript II Reverse Transcriptase (Invitrogen) and $3^{\prime} \mathrm{RT} / \mathrm{PCR}$ primer. This enzyme displays terminal transferase activity and adds three $\mathrm{C}$ residues at the $3^{\prime}$ end of the newly synthesized cDNA. For the synthesis of the second strand (carried out in the same tube) and consecutive PCR amplification the primer with three G at the $3^{\prime}$ end and the BanI restriction site $\left(5^{\prime} \mathrm{RT} / \mathrm{PCR}\right.$ primer) was used. The final RT-PCR products were purified (by phenol-chloroform extraction), digested with BanI and subsequently concatamerized using T4 DNA ligase (Promega). The gel-purified concatamers (low melting point agarose) were ligated into TOPO-TA cloning vector. TOP10 electrocompetent cells were transformed with the ligation products and grown on a selective medium. Plasmids containing inserts were isolated from the individual colonies and sequenced using ABI PRISM 310 Genetic Analyzer.

The sequences of short RNAs extracted from gel were determined and their precursor RNA molecules were identified by a BLAST search against $A$. thaliana genome in the NCBI database (http://www.ncbi.nih.gov/BLAST/).

\section{Results}

The first step of our studies focused on 2D-PAGE optimization to ensure the best separation of short RNA molecules. To this end, we designed four RNA oligonucleotides named Oligo1-4. All of them were $40 \mathrm{nt}$ long but they differed in sequence, molecular mass, or secondary structure (Fig. 1). a

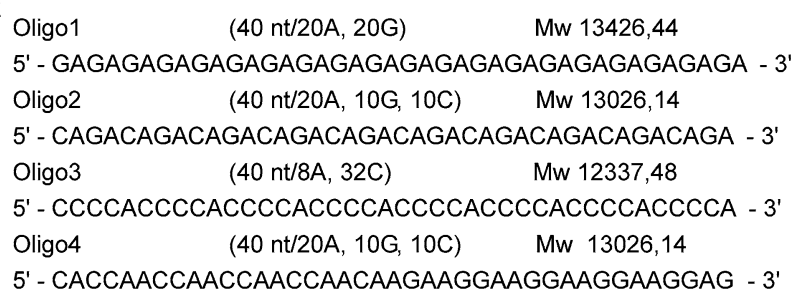

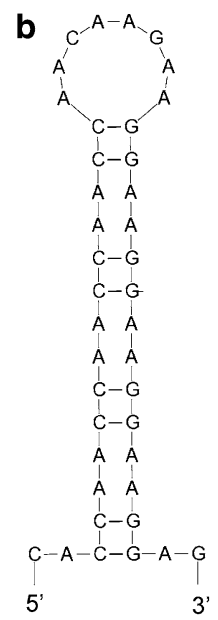

Fig. 1 Oligo1-4, used for optimizing 2D-PAGE conditions. a Sequences of oligonucleotides, b putative secondary structure adopted by Oligo- 4 at $37^{\circ} \mathrm{C}$

Oligo-1 had the highest molecular mass and was composed of $20 \mathrm{G}$ and $20 \mathrm{~A}$. Oligo-3, with the lowest molecular mass contained $8 \mathrm{~A}$ and $32 \mathrm{C}$. Oligo- 2 and Oligo- 4 were composed of the same nucleotides: $10 \mathrm{G}, 10 \mathrm{C}, 20 \mathrm{~A}$. They had the same molecular mass but their sequences were different. As a result, Oligo-2 did not form any stable secondary structure at $37^{\circ} \mathrm{C}$ (similarly to Oligo-1 and Oligo-3) while Oligo-4 adopted a stable hairpin structure at the same temperature. All four oligonucleotides were labeled with ${ }^{32} \mathrm{P}$ at the $5^{\prime}$-end, mixed in equimolar concentration, and subjected to 2D-PAGE under various conditions (in native, semidenaturing and denaturing gels). The chemically synthesized oligonucleotides were not gel-purified post synthesis, neither prior- nor post-labeling with ${ }^{32} \mathrm{P}$. As a result, the main product (40 nt oligonucleotide) was always accompanied by a small amount of shorter oligonucleotides. The latter could be observed during 2D-PAGE experiments. In this way we could better estimate the efficiency of RNA separation under different conditions.

The undertaken experiments demonstrated that 2DPAGE can be used for the analysis of short RNA molecules even if their length or molecular mass is quite similar. As it could be expected, the obtained pattern of RNA separation strongly depended on the applied conditions. In all cases, oligonucleotides of different molecular mass were well separated by 1D- and 2D-PAGE (Fig. 2). The application of 
Fig. 2 2D-PAGE of Oligo1-4 mixtures. Electrophoreses were performed under denaturing, semi-denaturing, and native conditions. Location of particular oligonucleotides are indicated with numbers (1-4) and arrows. Directions of the first dimension electrophoresis (1D) and the second dimension electrophoresis (2D) are indicated by black arrows

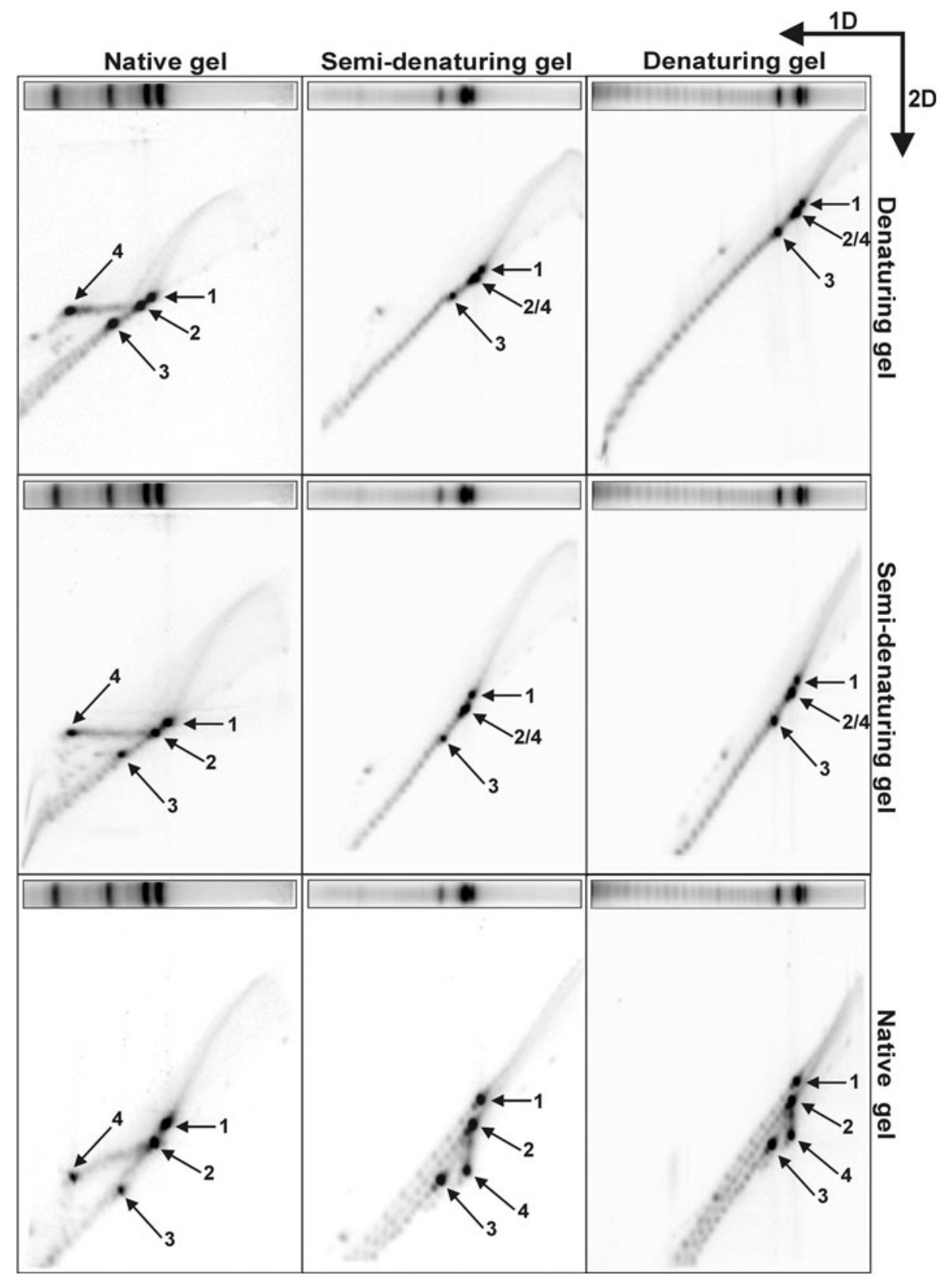

native gel for electrophoresis in the first or second dimension permitted us to distinguish among oligonucleotides with the same molecular mass but different secondary structures.

In the next series of experiments we attempted to determine whether 2D-PAGE enables an effective analysis of complex mixtures containing short RNA molecules. Taking into account the above observations we used three combinations of gels: native/denaturing, denaturing/native and semi-denaturing/semi-denaturing. The fraction of RNA enriched in molecules shorter than $200 \mathrm{nt}$ was isolated from leaves of A. thaliana. After $5^{\prime}$-labelling with ${ }^{32} \mathrm{P}$ (exchange reaction) the RNA samples were subjected to 2D-PAGE. The obtained patterns of separation were markedly different and highly reproducible (Fig. 3). In contrast to the results obtained for Oligo1-4, 2D electrophoresis in native/ denaturing and denaturing/native gels did not produce expected highly resolved autoradiograms (Fig. 3a, c). Instead, the gels contained a small number of well-defined spots. The other spots were poorly split and often fuzzy. The analyzed mixtures of short RNAs were best separated when semi-denaturing gels were applied for electrophoresis in both dimensions. In the corresponding autoradiograms the highest number of well separated spots was detected (Fig. 3b).

The data presented above suggested that 2D-PAGE can be used for the analysis of complex mixtures composed of short RNA molecules. Unfortunately, we did not know whether the observed RNAs were indeed the products of 


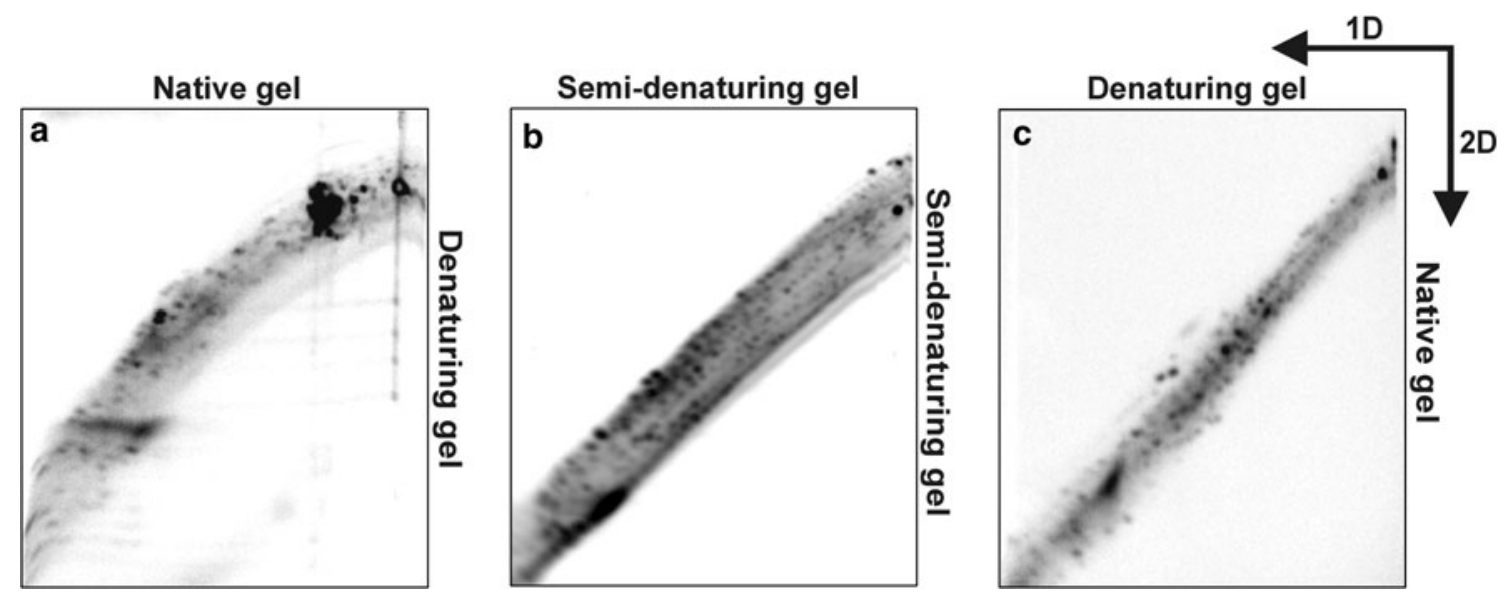

Fig. 3 2D-PAGE-based analysis of RNA (fraction enriched in RNA shorter than $200 \mathrm{nt}$ ) isolated from A. thaliana leaves. Electrophoreses were performed under native/denaturing (a), semi-denaturing/semi-

degradation. Recent studies indicated that the fraction of RNA between 30 and $80 \mathrm{nt}$ can be especially rich in this type of molecules (longer than siRNA/miRNA and shorter than tRNA) [4, 6, 18-25]. Accordingly, we attempted to determine the nature of the selected RNA visualized in 2D gels. The RNAs extracted from the 20 most intense spots (Fig. $3 b$ ) were mixed together and amplified by RT-PCR. The obtained cDNA was concatamerized, cloned and sequenced. The sequencing of 150 clones let us to identify 20 RNAs. Their length ranged from 19 to $86 \mathrm{nt}$ but half of them (10) were 28-38 nt long. A computational analysis involving $A$. thaliana genome database revealed that the majority of the sequenced cDNA clones (19) represented the products of tRNA (9), rRNA (8), mRNA (1) and snRNA (1) degradation (Table 1). One molecule was classified as an unknown transcript of the intergenic region. Several mismatches to the A. thaliana genomic sequence were detected during BLAST search. Since they appeared only in tRNA-derivatives, it is highly plausible that these mismatches reflect modified bases in tRNA.

Finally, we tried to determine whether 2D-PAGE can be used to identify specific profiles of RNA degradation in various cells/tissues/organs or in the same type of cells/ tissues/organs but growing in different conditions. For this purpose, fractions of RNA enriched in molecules shorter than $200 \mathrm{nt}$ were extracted from different plant organs and from human cell lines and subjected to 2D-PAGE under semi-denaturing conditions.

The exemplary autoradiograms presented in Figs. 3, 4 and 5 suggest that the generated patterns of RNA degradant accumulation are cell- or organo-specific. In Fig. 4 we compared RNA extracted from L. luteus roots (Fig. 4a) and from young nodules forming on $L$. luteus roots infected with symbiotic bacteria (Fig. 4b). In Fig. 5 RNA isolated from HeLa and HL60 cell lines were compared. In both denaturing (b) and denaturing/native (c) conditions in the first and second dimension, respectively. The direction of electrophoresis in the first and second dimensions is indicated by arrows

cases significant qualitative and quantitative differences in individual RNA accumulation were observed. In general, the obtained results indicate that 2D-PAGE is a very effective fast and cheap technique that can be applied for the analysis of high copy number RNA degradants. It can be an interesting alternative to other classic techniques such as northern blot hybridization or standard sequencing.

\section{Discussion}

Although developed over 30 years ago and successfully applied for fractionation of tRNA and structural analysis of viral RNA [14, 26-29] the 2D-PAGE technique had not found many applications in RNA-related areas. Recently it has been shown that this method is suitable for the analysis of oligonucleotide mixtures [9, 30, 31]. In this study, we demonstrated that 2D-PAGE can be successfully applied for analyzing RNA degradants ranging in size from $\sim 10$ to $\sim 90$ nt.

The experiments carried out in distinct electrophoretic conditions revealed that 2D-PAGE enables an effective fractionation of RNA molecules even if they have the same length but different base composition or secondary structure. Our results indicate that the application of native gels in the first or second dimension is the best choice for analyzing a limited number of small-sized RNA molecules. We also observed that 2D-PAGE under semi-denaturing/ semi-denaturing conditions is the best option if one wishes to examine very complex and diversified pools of RNA extracted from cells/tissues/organs. The electrophoresis in native gels preserves the intra- and intermolecular interactions. As a result, the analyzed RNAs are not well resolved because they can adopt various conformations or form multimolecular complexes. In contrast, under semi- 


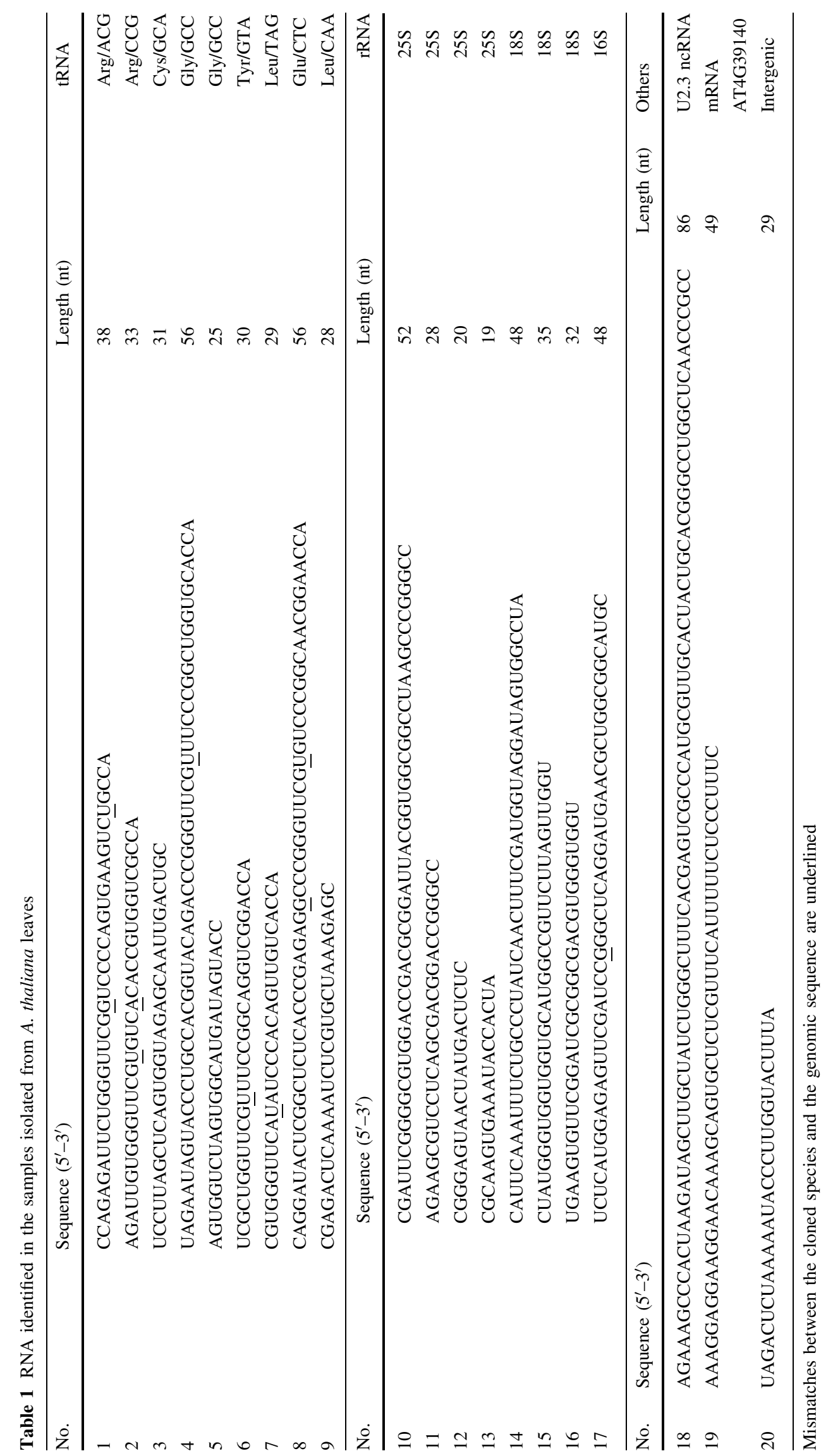



analysis of short RNA isolated from Lupinus luteus roots (a) and nodules forming on the Lupinus luteus roots 9 dayspost-infection with symbiotic bacteria (b). The direction of electrophoresis in the first and second dimensions is indicated by arrows
Fig. 4 Comparative 2D-PAGE

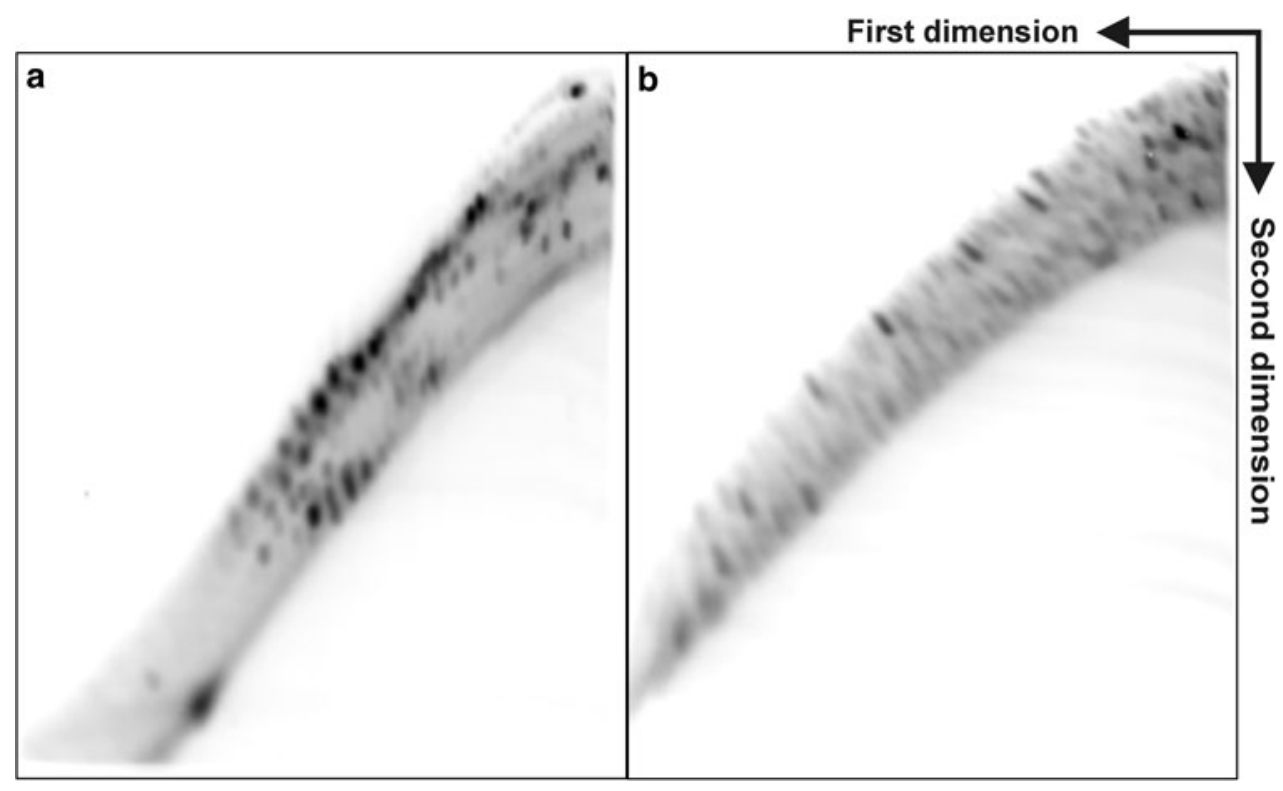

Fig. 5 Comparative 2D-PAGE analysis of short RNA isolated from HeLa (a) and HL60 (b) cells. The direction of electrophoresis in the first and second dimensions is indicated by arrows

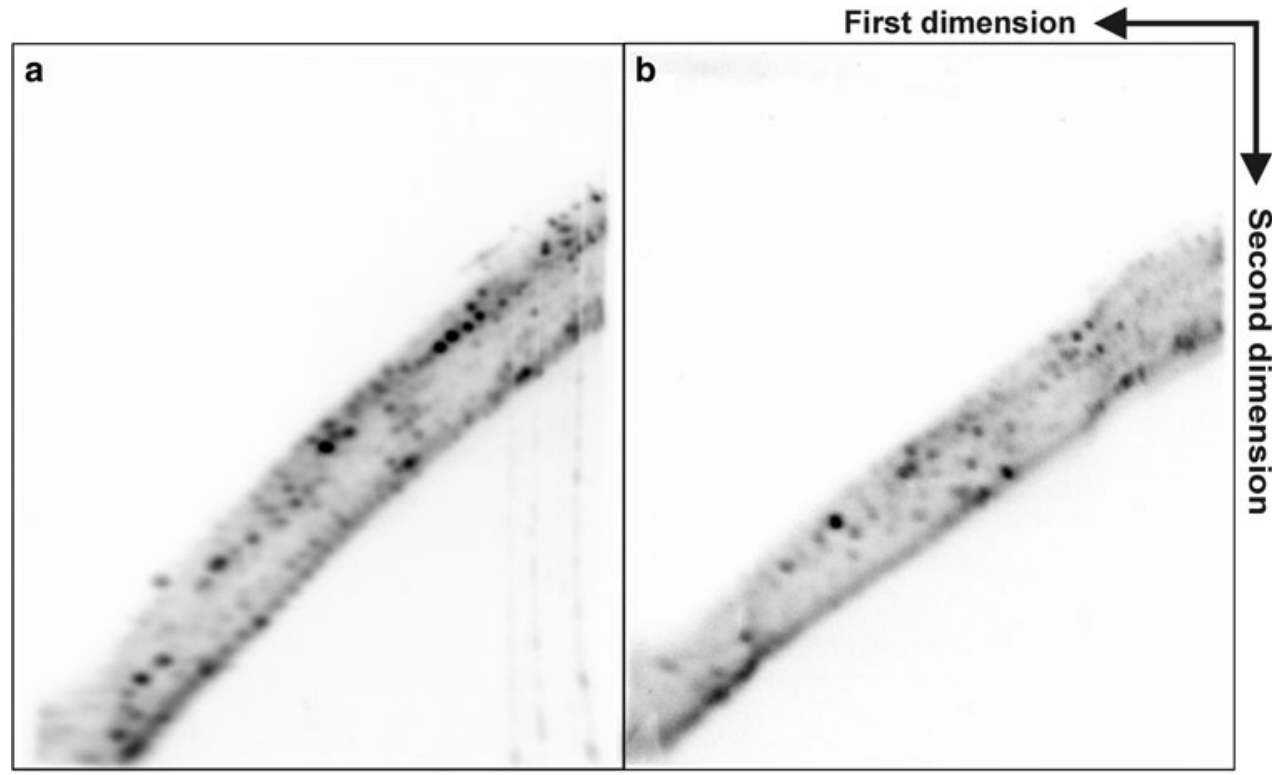

denaturing conditions only very stable structures can be preserved. As a result the majority of RNA molecules migrate as individual well-separated spots.

Recently, it has been shown that some of RNA degradation intermediates can accumulate in cells instead of being hydrolyzed to single nucleotides [4, 6, 18-25]. Accordingly, we hypothesized that a large fraction of RNA molecules observed in 2D gels (especially, molecules shorter than tRNAs and longer than miRNAs) might be products of RNA degradation. Cloning and sequencing of RNAs extracted from the most intensive spots confirmed our assumption. It turned out that out of 20 analyzed RNAs, 19 could be classified as degradants. They were identified as fragments of tRNA, rRNA, mRNA and snRNA. The obtained results also suggest that the composition of RNA degradome can be cell/tissue/organospecific. It seems that the profiling of RNA degradant accumulation can provide some information about physiological or pathological processes occurring in examined cells or organisms. Therefore, RNA degradome components could be considered as potential biomarkers in monitoring developmental processes, stress responses, or host-pathogen interactions.

In general, it seems that 2D-PAGE is an effective tool for analyzing high copy number RNA degradants. The undertaken studies disclosed many advantages of this technique. It permits fast comparison of RNA degradomes isolated from cell lines, tissues or organs. Unlike northern blots or DNA microarrays it does not require sequencing of individual degradants prior to their analysis. In addition, it restricts the 
number of analyzed individuals to those accumulating to relatively high levels. 2D-PAGE also allows us to quickly monitor changes occurring in RNA degradome under the influence of endogenous or exogenous factors. Finally, this method can be used to identify novel classes of small RNAs analogous to the already found sno-derived RNA degradants [5] or tRNA-derived RNA degradants [8, 32].

Acknowledgments This work was supported by the Polish Government through a grant from the Ministry of Science and Higher Education [PBZ-MNiI-2/1/2005 to M.F.]. The authors would like to thank Dr. Zbigniew Michalski and Justyna Serba for their excellent technical assistance.

Open Access This article is distributed under the terms of the Creative Commons Attribution Noncommercial License which permits any noncommercial use, distribution, and reproduction in any medium, provided the original author(s) and source are credited.

\section{References}

1. Houseley J, Tollervey D (2009) The many pathways of RNA degradation. Cell 136(4):763-776. doi:10.1016/j.cell.2009.01.019

2. Mattick JS, Makunin IV (2006) Non-coding RNA. Hum Mol Genet 15(Spec No 1):R17-R29. doi:10.1093/hmg/dd1046

3. Waters LS, Storz G (2009) Regulatory RNAs in bacteria. Cell 136(4):615-628. doi:10.1016/j.cell.2009.01.043

4. Thompson DM, Lu C, Green PJ, Parker R (2008) tRNA cleavage is a conserved response to oxidative stress in eukaryotes. RNA 14(10):2095-2103. doi:10.1261/rna.1232808

5. Taft RJ, Glazov EA, Lassmann T, Hayashizaki Y, Carninci P, Mattick JS (2009) Small RNAs derived from snoRNAs. RNA 15(7):1233-1240. doi:10.1261/rna.1528909

6. Zhang S, Sun L, Kragler F (2009) The phloem-delivered RNA pool contains small noncoding RNAs and interferes with translation. Plant Physiol 150(1):378-387. doi:10.1104/pp.108.134767

7. Ender C, Krek A, Friedlander MR, Beitzinger M, Weinmann L, Chen W, Pfeffer S, Rajewsky N, Meister G (2008) A human snoRNA with microRNA-like functions. Mol Cell 32(4): 519-528. doi:10.1016/j.molcel.2008.10.017

8. Haussecker D, Huang Y, Lau A, Parameswaran P, Fire AZ, Kay MA (2010) Human tRNA-derived small RNAs in the global regulation of RNA silencing. RNA 16(4):673-695. doi:10.1261/ rna. 2000810

9. Huttenhofer A, Vogel J (2006) Experimental approaches to identify non-coding RNAs. Nucleic Acids Res 34(2):635-646. doi:10.1093/nar/gkj469

10. Lister R, Gregory BD, Ecker JR (2009) Next is now: new technologies for sequencing of genomes, transcriptomes, and beyond. Curr Opin Plant Biol 12(2):107-118. doi:10.1016/j.pbi.2008.11.004

11. Boyes DC, Zayed AM, Ascenzi R, McCaskill AJ, Hoffman NE, Davis KR, Gorlach J (2001) Growth stage-based phenotypic analysis of Arabidopsis: a model for high throughput functional genomics in plants. Plant Cell 13(7):1499-1510

12. Strozycki PM, Szczurek A, Lotocka B, Figlerowicz M, Legocki AB (2007) Ferritins and nodulation in Lupinus luteus: iron management in indeterminate type nodules. J Exp Bot 58(12): 3145-3153. doi:10.1093/jxb/erm152

13. Strozycki PM, Skapska A, Szczesniak K, Sobieszczuk E, Briat JF, Legocki AB (2003) Differential expression and evolutionary analysis of the three ferritin genes in the legume plant Lupinus luteus. Physiol Plant 118(3):380-389
14. Fradin A, Gruhl H, Feldmann H (1975) Mapping of yeast tRNAs by two-dimensional electrophoresis on polyacrylamide gels. FEBS Lett 50(2):185-189

15. Lau NC, Lim LP, Weinstein EG, Bartel DP (2001) An abundant class of tiny RNAs with probable regulatory roles in Caenorhabditis elegans. Science 294(5543):858-862. doi:10.1126/ science. 1065062

16. Chappell L, Baulcombe D, Molnar A (2006) Isolation and cloning of small RNAs from virus-infected plants. Curr Protoc Microbiol Chapter 16: Unit 16H 12. doi:10.1002/9780471729259.mc16h02s00

17. Lee RC, Ambros V (2001) An extensive class of small RNAs in Caenorhabditis elegans. Science 294(5543):862-864. doi:10. 1126/science. 1065329

18. Lee SR, Collins K (2005) Starvation-induced cleavage of the tRNA anticodon loop in Tetrahymena thermophila. J Biol Chem 280(52):42744-42749. doi:10.1074/jbc.M510356200

19. Haiser HJ, Karginov FV, Hannon GJ, Elliot MA (2008) Developmentally regulated cleavage of tRNAs in the bacterium Streptomyces coelicolor. Nucleic Acids Res 36(3):732-741. doi: 10.1093/nar/gkm1096

20. Jochl C, Rederstorff M, Hertel J, Stadler PF, Hofacker IL, Schrettl M, Haas H, Huttenhofer A (2008) Small ncRNA transcriptome analysis from Aspergillus fumigatus suggests a novel mechanism for regulation of protein synthesis. Nucleic Acids Res 36(8):2677-2689. doi:10.1093/nar/gkn123

21. Kawaji H, Nakamura M, Takahashi Y, Sandelin A, Katayama S, Fukuda S, Daub CO, Kai C, Kawai J, Yasuda J, Carninci P, Hayashizaki Y (2008) Hidden layers of human small RNAs. BMC Genomics 9:157. doi:10.1186/1471-2164-9-157

22. Li Y, Luo J, Zhou H, Liao JY, Ma LM, Chen YQ, Qu LH (2008) Stress-induced tRNA-derived RNAs: a novel class of small RNAs in the primitive eukaryote Giardia lamblia. Nucleic Acids Res 36(19):6048-6055. doi:10.1093/nar/gkn596

23. Yamasaki S, Ivanov P, Hu GF, Anderson P (2009) Angiogenin cleaves tRNA and promotes stress-induced translational repression. J Cell Biol 185(1):35-42. doi:10.1083/jcb.200811106

24. Elbarbary RA, Takaku H, Uchiumi N, Tamiya H, Abe M, Takahashi M, Nishida H, Nashimoto M (2009) Modulation of gene expression by human cytosolic tRNase $\mathrm{Z}(\mathrm{L})$ through $5^{\prime}$-halftRNA. PLoS One 4(6):e5908. doi:10.1371/journal.pone.0005908

25. Hsieh LC, Lin SI, Kuo HF, Chiou TJ (2010) Abundance of tRNA-derived small RNAs in phosphate-starved Arabidopsis roots. Plant Signal Behav 5(5)

26. de Wachter R, Fiers W (1972) Preparative two-dimensional polyacrylamide gel electrophoresis of 32 P-labeled RNA. Anal Biochem 49(1):184-197

27. Lee YF, Wimmer E (1976) "Fingerprinting" high molecular weight RNA by two-dimensional gel electrophoresis: application to poliovirus RNA. Nucleic Acids Res 3(7):1647-1658

28. Stein M, Varricchio F (1974) Separation of t-RNAs by twodimensional polyacrylamide gel electrophoresis. Anal Biochem 61(1):112-119

29. Martin RP, Schneller JM, Stahl AJ, Dirheimer G (1977) Study of yeast mitochondrial tRNAs by two-dimensional polyacrylamide gel electrophoresis: characterization of isoaccepting species and search for imported cytoplasmic tRNAs. Nucleic Acids Res 4(10):3497-3510

30. Shiraishi H (2004) Two-dimensional fractionation of complex mixture of oligonucleotides in microRNA size range. Nucleic Acids Symp Ser (Oxf) (48):293-294. doi:10.1093/nass/48.1.293

31. Hokii Y, Kubo A, Ogasawara T, Nogi Y, Taneda A, Arai R, Muto A, Ushida C (2006) Twelve novel C.elegans RNA candidates isolated by two-dimensional polyacrylamide gel electrophoresis. Gene 365:83-87. doi:10.1016/j.gene.2005.09.039

32. Lee YS, Shibata Y, Malhotra A, Dutta A (2009) A novel class of small RNAs: tRNA-derived RNA fragments (tRFs). Genes Dev 23(22):2639-2649. doi:10.1101/gad.1837609 